\title{
Correction: “Topical treatment for acute phase Peyronie's disease utilizing a new gel, H100: a randomized, prospective, placebo-controlled pilot study"
}

\section{J. Twidwell • L. Levine}

Published online: 2 June 2020

(c) The Author(s), under exclusive licence to Springer Nature Limited 2020

Correction to: International Journal of Impotence Research https://doi.org/10.1038/ijir.2015.22

The authors disclose a potential financial conflict of interest due to their relationship with Hybrid Medical, the makers of $\mathrm{H} 100$.

JT is the inventor of $\mathrm{H} 100$ and is the Chairman of Hybrid Medical.

Mr Hoium is a coinventor of $\mathrm{H} 100$ and is the President of Hybrid Medical.

LL is an unpaid Medical Advisor who assisted in study development and was coauthor of the manuscript.
Whilst the study was funded by Hybrid Medical, no investigator received any direct or indirect financial compensation for the development, completion, analysis, or publication of this study.

The study was performed under strict IRB guidance. The study was double blind and placebo controlled to minimize any possibility of investigator bias.

The authors apologize for omitting this information when the manuscript was published and had no intentions of misleading readers. 